\title{
Identification of Mite Types Infesting Cucumis Sativus at Al Monshah District, Sohag Governorate, Egypt
}

\author{
Abd El-Aleem Saad Soliman Desoky* \\ Plant protection Department (Agricultural Zoology), Faculty of Agriculture, Sohag University, Egypt. \\ *Corresponding Authors: Abd El-Aleem Saad Soliman Desoky, Plant protection Department \\ (Agricultural Zoology), Faculty of Agriculture, Sohag University, Egypt.
}

\begin{abstract}
The study was carried out at $\mathrm{Al}$ Monshah District, Sohag Governorate, Egypt to identify of mites species infesting cucumber plants, Cucumis sativus L during March-June 2020. The results showed that found one mites species was two-spotted spider mite Tetranychus urticae Koch. The red spider lives at the beginning of the infestation on the lower surface of the leaves to feed on the absorption of succulents, so that the affected leaves appear faded spots, and with the increase of the injury the spots increase and collect and turn into a light brown to make the whole leaf dry brown, and note the silk threads that the spider secretes on the bottom surface of the paper where the dust collects With spider waste, the paper becomes dirty.

Red spider sews strings to move from one leaf to another, and the plant is covered with fine strings that the spider witnesses to move from one leaf to another and from one plant to another, and its members have the ability to carry some pesticides and form impregnable strains by repeating the use of pesticides. It leads to a decrease in the value of the product and a reduction in production and income. The results obtained in the present study should be taken into account in planning programs when conducting the integrated management on Tetranychus urticae Koch.
\end{abstract}

Keywords: cucumber plants, Cucumis sativus, Tetranychus urticae, two-spotted spider, red spider.

\section{INTRODUCTION}

Cucumber plant is one of the most popular vegetables in Egypt.( Abdel-Rahman, 2019). Cucumber, Cucumis sativus $\mathrm{L}$, is one of the most important delicious vegetable crops among the family Cucurbitaceae and it is consumed as a raw green fruit or in salads and pickles. In Egypt, in 2017 the total cucumber production recorded 488.723 tons (FAO, 2017). The cucumber, Cucumis sativus L, is a new greenhouse crop which can be grown successfully under protective structures year-round. Several insect pests that cause stunting plant and low yield attack cucumber crop; as a result, these pests must be controlled for optimal crop production (Bashir and Abdalhadi, 1986).

It is well known that cucumber is a subject to the infestation by many pest species especially phytophagous mites in the family Tetranychidae.

The two-spotted spider mite, Tetranychus urticae Koch is one of the most dangerous mite pest infesting a wide range of plants worldwide (Zaher, 1986 a; Abdel Rahman \& Fouly, 2001 and Zhang, 2003). The abovementioned vegetable plants are liable to be infested by several phytophagous mites, Tetranychus urticae Koch; Tetranychus cucurbitacearum that cause severe damage to the plants by feeding on the plant sap in addition to plant viruses transmission (Farrag et al., 1998 \& Abou Attia et al., 2004). The aim of this study is to identify of mite species that affect the cucumber plants.

\section{Materials ANd Methods}

The study was carried out in five different fields at Al Monshah District, Sohag Governorate, Egypt during March to June 2020. In each field, ten random samples of cucumber leaves, Cucumis sativus L were taken weekly from different parts and levels of the plant. The leaves of the plant samples were placed in plastic bags and transferred to the place of examination using a binocular microscope. The identification of phytophagus mite species was done using certain keys illustrated by Krantz, 1978; Zaher, 1986 b \& c and Evans, 1992. 


\section{RESULTS AND DISCUSSION}

Table(1). mites species infesting cucumber plants at $\mathrm{Al}$ Monshah District, Sohag Governorate, during March to June 2020.

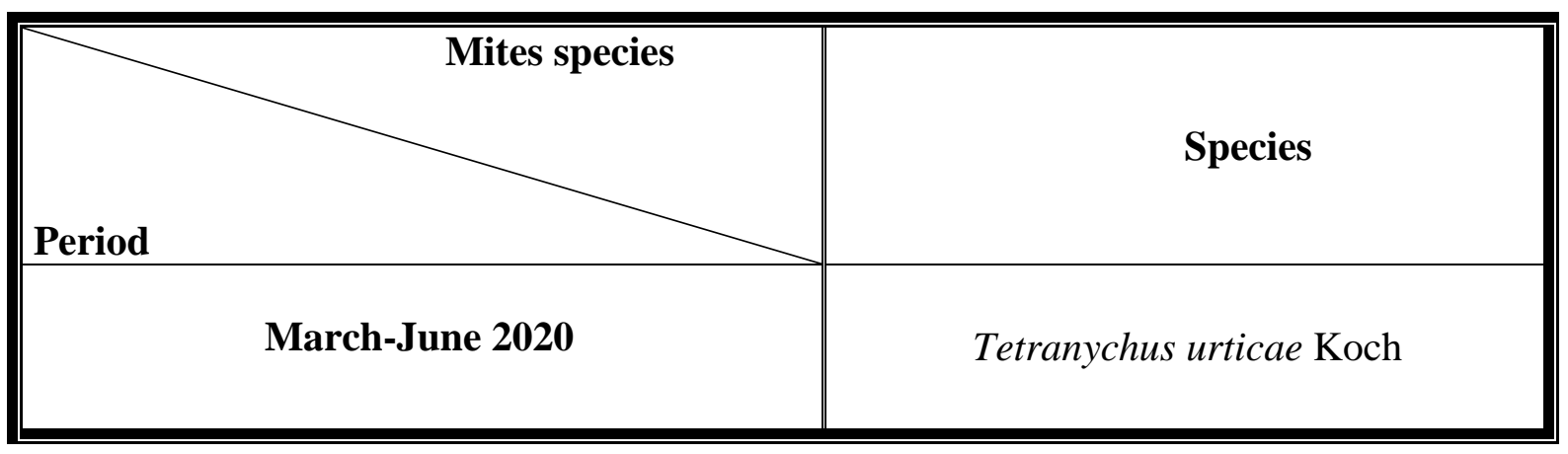

Taxonomic Tree

- kingdom Animalia

- $\quad$ Sub kingdom: Metazoa

- $\quad$ Phylum: Arthropoda

- $\quad$ Subphylum: Chelicerata

- $\quad$ Class: Arachnida

- Subclass: Acari

- $\quad$ Superorder: Acariformes

- $\quad$ Suborder: Prostigmata

- $\quad$ Family: Tetranychidae

- $\quad$ Genus: Tetranychus

- $\quad$ Species: Tetranychus urticae

The data presented in Table 1 showed the presence of Tetranychus urticae Koch, one species of mites collected from Cucumis sativus L in the study area, It has also been shown that Tetranychus urticae Koch is most is the most higher prevalent and infested on cucumber plants. The results of this study showed effect of feeding duration and initial infestation density of Tetranychus urticae Koch on the foliage and yield attributes of cucumber. Mite incidence causes chlorosis in the leaves resulting in enormous loss in the total photosynthates of the plant followed by reduced yield. Thus, early identification of Tetranychus urticae Koch incidence and implementation of treatment should minimize yield loss, allowing potential higher benefit to the growers.

Our results were similar with: Rai and Inderajeet (2011) reported Tetranychus urticae Koch infesting many vegetables like cucumber. Tehri et al.(2014) Increased activity of Tetranychus urticae Koch population was considered to play an active role in causing foliar damage and yield losses. There was a significant negative correlation between Tetranychus urticae infestation density and various attributes under investigation which emphasized the fact that quantitative losses occurred due to Tetranychus urticae Koch infestation in cucumber and as low as 5 mites released per grown up leaf (less than 1 mite/ sq. cm leaf) was capable of causing significant damage to the crop.

\section{CONCLUSiON}

The results obtained in this study should be taken into consideration in the future to work the following research studies:

- Identification the types of mites spread on all agricultural crops in the region

- Conduct biological and ecological studies and population fluctuations for red spider

- Study integrated control programs for the red spider, which includes prevention methods, agricultural, mechanical processes and natural enemies such as predatory mites, and finally the study and evaluation of the best acaricides. 


\section{REFERENCES}

[1] Abdel-Rahman, H. R.(2019).Toxicological and Biological Responses of Tetranychus urticae Koch to Three Pesticides and their Side Effect on the Predatory Mite, Euseius scutalis (A.-H.). J. of Plant Protection and Pathology, Mansoura Univ., Vol 10 (12):639-646.

[2] Abdel Rahman, H.R. and Fouly, A.H. (2001). Residual analysis of some pesticides in sweet pepper and their side effect on non-target mite species in greenhouses. J. Agric. Sci., Mansoura Univ., 26(1): 459-465.

[3] Abou-Attia, F.A.; Sharshir, F.A.; Tadros, M.S. and El-Shafei, G.M.A. (2004).Relative abundance and spatial distribution of Liviomyza trifolii (Burgees), Thrips tabaci (Lind.) and Tetranychus urticae Koch populations attacking cucumber and tomato grown undergreen houses. J.Agric. Res. Tanta Univ., 30 (2): 342-357.

[4] Bashir, N.H.H, Abdalhadi M.A. (1986). Screening of some insecticides against cucumber insect pests in the Sudan Gezira. Iraqi J. Agric. Sci., 4: 39-45.

[5] FAO (2017). FAO Stat database available from http://faostat:fao.org. Accessed date.

[6] Evans, J. (1992). Plantation Forestry in the Tropics. 2nd. Edn. Clarendon Press, Oxford 403pp.

[7] Farrag, A.M.; Megali, M.K. and Habashi, N.H. (1998). Survey of mites inhabiting cucurbitaceous and leguminous vegetables in Qualiobia and Giza Governorates. Egypt J. Agric. Res., 76 (1): 63-68.

[8] Krantz, G.W. (1978). A Manual of Acarology. Second Edition. Oregon State University Book Stores, Inc., Corvallis, Oregon. Second Printing (emended 1986): [i]-vii, [1]-509.

[9] Rai, S.N and Indrajeet. (2011). Note on phytophagous mites associated with common vegetables in Varanasi and Azamgarh district of Eastern Uttar Pradesh. J Insect Sci. 24(2): 199-200.

[10] Tehri, K.; Gulati, R. and Geroh, M. (2014). Damage potential of Tetranychus urticae Koch to cucumber fruit and foliage: Effect of initial infestation density. Journal of Applied and Natural Science 6 (1): 170176.

[11] Zaher, M.A. (1986a). Predaceous and non-phytophagous mites in Egypt (Nile Vally and Delta) PI 480 Program. USA Project No. EG. ARS, 30. Grant. No, FG, Eg., 139, pp 567.

[12] Zaher, M.A. (1986 b). Survey and ecological studies on phytophagous, predaceous and soil mites in Egypt.II-B: Predaceous and non phytophagous mites in Egypt. (Nile Valley and Delta): 567 pp.

[13] Zaher, M.A. (1986 c). Survey and ecological studies on phytophagous, predaceous and soil mites in Egypt. III-C: Mites of Sinai: $36 \mathrm{pp}$.

[14] Zhang, Z. Q. (2003). Mites of Greenhouses; Identification, Biology and Control. CABI Publishing. Wallingford. UK.

Citation: Abd El-Aleem Saad Soliman Desoky, "Identification of Mite Types Infesting Cucumis Sativus at Al Monshah District, Sohag Governorate, Egypt" International Journal of Research Studies in Agricultural Sciences (IJRSAS), 2020; 6(7), pp. 24-26, http://dx.doi.org/10.20431/2454-6224.0607004

Copyright: (C) 2020 Authors. This is an open-access article distributed under the terms of the Creative Commons Attribution License, which permits unrestricted use, distribution, and reproduction in any medium, provided the original author and source are credited. 